\title{
Expresión de los Genes de los Receptores TCR $\gamma \delta$ en la Mucosa Yeyunal de Crías de Alpaca (Vicugna pacos)
}

\author{
Expression of TCR $\gamma \delta$ Receptor Genes in Jejunum Mucosa of Baby Alpacas \\ (Vicugna pacos)
}

\author{
Simón Mendizábal J. ${ }^{1}$, Alberto Manchego S. ${ }^{1,4}$, Gina Castro S. ${ }^{1}$, Mercy Ramirez V. ${ }^{1}$, \\ Nieves Sandoval C. ${ }^{2}$, Danilo Pezo C. ${ }^{3}$
}

\section{Resumen}

El objetivo de este estudio fue determinar la expresión de genes del receptor TCR $\gamma \delta$ (gamma y delta) en el epitelio yeyunal de 16 crías de alpaca aparentemente sanas, de 2 a 47 días de edad, mediante la cuantificación de ARN mensajero (ARNm) utilizando cebadores específicos. Se tomaron porciones de yeyuno ( $2 \mathrm{~cm}$ de longitud). El ARNm total de la mucosa de la porción media del yeyuno actuó como molde para la síntesis de ADN complementario mediante transcripción reversa (RT), seguida de un PCR-tiempo real para la amplificación y cuantificación de los ARNm de los polipéptidos que conforman las cadenas gamma y delta del TCR. Se utilizó el método $2^{-\Delta \Delta C t}$ para la cuantificación relativa de ARNm, teniendo como calibrador a dos crías neonatas que no habían consumido calostro. Las crías de 1, 2, 3 y $\geq 4$ semanas de edad expresaron el gen gamma en 4.75, $6.78,16.24$ y 103.11 veces lo expresado por los animales calibradores, respectivamente, y el gen delta fue expresado en 9.43, 20.78, 25.08 y 146.46 veces, respectivamente. Los resultados demuestran que los genes gamma y delta se expresan en forma creciente con la edad, y significativamente a partir de la cuarta semana de edad $(\mathrm{p}<0.05)$, indicando que los linfocitos $\mathrm{T} \gamma \delta$ se incrementan en la mucosa intestinal con la edad.

Palabras clave: alpacas; TCR; gamma; delta; RT-PCR tiempo real; cuantificación relativa

\footnotetext{
${ }^{1}$ Laboratorio de Microbiología y Parasitología Veterinaria, ${ }^{2}$ Laboratorio de Histología, Embriología y Patología Veterinaria, Facultad de Medicina Veterinaria, Universidad Nacional Mayor de San Marcos, Lima, Perú

${ }^{3}$ Estación Experimental Maranganí, Instituto Veterinario de Investigaciones Tropicales y de Altura (IVITA), Universidad Nacional Mayor de San Marcos, Cusco, Perú

${ }^{4}$ E-mail: amanchegos@gmail.com
}

Recibido: 13 de marzo de 2017

Aceptado para publicación: 6 de septiembre de 2017 
The aim of this study was to determine the expression of TCR $\gamma \delta$ receptor genes (gamma and delta) in the jejunal epithelium of 16 apparently healthy baby alpacas ( 2 to 47 days of age), by quantifying messenger RNA (mRNA) using specific primers. Jejunum samples ( $2 \mathrm{~cm}$ long) were collected. Total mRNA of the medium portion of the jejunum acted as template for complementary DNA synthesis by reverse transcription (RT), followed by real-time PCR for the amplification and quantification of the mRNAs of the polypeptides that make up the gamma and delta chains of the TCR. The $2^{-\Delta \Delta C t}$ method was used for the relative mRNA quantification, using as calibrator two neonatal alpacas that had not consumed colostrum. The alpacas of 1, 2, 3 and $\geq 4$ weeks of age expressed the gamma gene at 4.75, 6.78, 16.24 and 103.11 folds as expressed by the calibrator animals, respectively, and the delta gene was expressed at 9.43, 20.78, 25.08, and 146.46 folds, respectively. The results demonstrate that gamma and delta genes are increasingly expressed with age, and significantly from the fourth week of age $(\mathrm{p}<0.05)$, indicating that $\mathrm{T} \gamma \delta$ lymphocytes increase in the intestinal mucosa with age.

Key words: alpaca; TCR; gamma; delta; RT-PCR real time; relative quantification

\section{INTRODUCCIÓN}

La alta mortalidad de crías de alpacas y llamas en las comunidades y empresas agropecuarias en la puna de la sierra peruana, a causa de enfermedades infecciosas (FAO, 2005; Mamani et al., 2009), crea la necesidad de tener un mayor y mejor conocimiento de la fisiopatología de estas enfermedades.

Se han hecho importantes avances en la identificación de los agentes infecciosos y se ha determinado la participación de las bacterias Clostridium perfringens y E. coli, de los rotavirus y coronavirus y de los parásitos Eimeria spp y Cryptosporidium spp en los complejos entéricos de las crías (Rojas et al., 2016); sin embargo, existe escaso conocimiento de la respuesta inmune de la mucosa intestinal de las alpacas, sobre todo de las crías, que permita comprender la participación del sistema inmune en el desarrollo de la fisiopatología de las enfermedades y los métodos para tratarlas y prevenirlas. No obstante, el tracto intestinal es una de las principales puertas de entrada para los microorganismos patógenos $\mathrm{y}$, a su vez, una de las superficies corporales donde tales microorganismos se detectan y son combatidos (Tizard, 2002; More, 2013).

En la mucosa intestinal de otros animales domésticos, como la vaca, se desarrollan respuestas inmunes innatas de tipo celular que incluyen linfocitos especializados, denomina$\operatorname{dos} \mathrm{T} \gamma \delta$ (por su estructura de receptor de linfocitos T [TCR]), que están en mayor concentración en esta área y cumplen un rol vital en la protección de las mucosas al actuar como células efectoras y también estimuladoras del sistema inmune adaptativo (Haas et al., 1993). En los rumiantes, los linfocitos $\mathrm{T} \gamma \delta$ también se encuentran en altas concentraciones a nivel sanguíneo y esa concentración es mayor cuando son jóvenes. Dichos linfocitos son necesarios para una inmunorreacción celular temprana en animales cuyas inmunoglobulinas no atraviesan la placenta (Guzman et al., 2014).

Los linfocitos presentes en la mucosa intestinal son células estratégicamente localizadas, compuestas por células heterogéneas que tienen un papel importante en la inmunidad local. Estos linfocitos intraepiteliales (IEL) y los que conforman la lámina propia de 
linfocitos (LPL) ocupan anatómicamente distintos compartimentos y difieren significativamente en el fenotipo, función y morfología. Los linfocitos IEL en ratones expresan los receptores gamma delta junto al CD8 en su superficie a diferencia del timo y sangre que son CD4- y CD8-(Croitoru et al., 1990), mientras que en ovejas solo un $18 \%$ de los linfocitos IEL fueron TRC $\gamma \delta \mathrm{y}$, de ellos, el 54\% fueron CD8 ${ }^{+}$(Gyorffy et al., 1992), indicando que existen diversas subpoblaciones linfoides en la mucosa intestinal de los animales.

En el presente trabajo se investiga la expresión de los genes de los polipéptidos gamma y delta que conforman el TCR de los linfocitos en la mucosa intestinal de las crías de alpacas, hipotetizando que la expresión de los genes del TCR $\gamma \delta$ en la mucosa intestinal de yeyuno de crías de alpaca se incrementa en las primeras semanas de vida. En este estudio, el objetivo principal fue determinar la expresión de los genes codificadores del $\mathrm{TCR} \gamma \delta$ en la mucosa intestinal de yeyuno de crías de alpacas.

\section{Materiales y Métodos}

\section{Animales}

Se utilizaron 16 crías de alpacas, clínicamente sanas, de 2 a 47 días de edad, de variedad Suri y Huacaya, sin distinción de sexo, provenientes del distrito de Maranganí, departamento de Cusco, Perú. Además, dos crías que no consumieron calostro sirvieron como puntos de referencia basales en el estudio (calibradores). Los animales se criaron en forma extensiva en pastos naturales sin vacunaciones.

Se formaron cuatro grupos etarios con cuatro animales por grupo: (I): 1-7 días; (II): 8-14 días; (III): 15-21 días: (IV): 21-47 días de edad.

\section{Muestras}

Los animales fueron manejados bajo el Protocolo de Autorización N. ${ }^{\circ}$ 2009-001 del Comité de Ética y Bienestar Animal de la Facultad de Medicina Veterinaria de la Universidad Nacional Mayor de San Marcos. Para el sacrificio se empleó $1.5 \mathrm{mg} / \mathrm{kg}$ de xilacina $\left(\right.$ Rompun ${ }^{\circledR}$ ) y $7.5 \mathrm{mg} / \mathrm{kg}$ de ketamina (Vetalar $\left.{ }^{\circledR}\right)$, vía intramuscular, con una sobredosis de $50 \mathrm{mg} / \mathrm{kg}$, vía endovenosa, de pentobarbital sódico (Halatal®). Inmediatamente después del sacrificio, se tomaron segmentos de $2 \mathrm{~cm}$ de longitud por animal del yeyuno; se lavaron con suero fisiológico estéril al $0.9 \%$ y se conservaron en nitrógeno líquido a $-196^{\circ} \mathrm{C}$.

\section{Expresión de TCR $\gamma \delta$}

\section{Extracción de ARN total}

Se empleó el método combinado de «Trizol ${ }^{\circledR}$ Reagent» y el kit comercial «PureLinkTM Micro-to-Midi System» (Invitrogen, EEUU) siguiendo las instrucciones del fabricante.

\section{Sintesis de $A D N$ complementario (ADNc)}

El ARN total extraído sirvió de base para la síntesis de ADNc por transcripción reversa (RT-PCR) empleando el termociclador Applied Biosystems ${ }^{\circledR} 2720$ y el kit comercial «SuperScript ${ }^{\mathrm{TM}}$ III FirstStrand Synthesis SuperMix for qRT-PCR» (Invitrogen, EEUU), siguiendo las instrucciones del fabricante.

\section{PCR Tiempo real}

El ADNc obtenido fue tomado como templado para la reacción de PCR en tiempo real. Se realizó en el termociclador Applied Biosystems ${ }^{\circledR} 7500$ empleando el kit comercial «SYBR ${ }^{\circledR}$ GreenER ${ }^{\mathrm{TM}}$ qPCR SuperMix Universal» siguiendo las instrucciones del fabricante. Se emplearon los cebadores di- 
señados por el programa Primer3Plus teniendo como secuencias el GenBank: JN172913.1 KF734 del gen gamma del TCR de Camelus dromedarius y el GenBank: KF734083.1 del gen delta del TCR de Vicugna pacos. Los resultados fueron evaluados a través del Software 7500 Fast Real-Time PCR Systems v. 2.0.1. Se obtuvieron los valores de ciclo umbral $(\mathrm{Ct})$ y el valor de temperatura de disociación $(\mathrm{Tm})$ de cada uno de los productos. Se hicieron tres repeticiones por muestra para obtener los promedios de $\mathrm{Ct}$ y Tm de cada muestra.

La cuantificación relativa de la transcripción reversa de los genes del TCR, gamma $(\gamma)$ y delta $(\delta)$, se realizó con el método delta delta Ct $\left(2^{-\Delta \Delta C t}\right)$ (Livak y Schmittgen, 2001; Pfaffl, 2001; Rebrikov y Trofimov, 2006).

\section{Análisis Estadístico}

Se utilizaron los resultados del método delta delta $\mathrm{Ct}\left(2^{-\Delta \Delta \mathrm{Ct}}\right)$ de los genes del TCR, gamma (ã) y delta (ä), por separado. En la prueba de Shapiro-Wilk se detectó ausencia de distribución normal, de allí que se utilizó la prueba de Kruskal-Wallis, pudiéndose detectar diferencia significativa entre algunos de los grupos, en ambos genes. Para las diferencias entre grupos se empleó la prueba de Kolmogorov-Smirnov de dos muestras (Steel y Torrie, 1988). Los datos se procesaron mediante el paquete estadístico STATA v. 14.0 , y se estableció la significación estadística en $5 \%$.

\section{Resultados}

\section{$\operatorname{Gen} \operatorname{Gamma}(\gamma)$}

\section{Expresión del gen}

Los valores de $\mathrm{Ct}$ de las muestras se encontraron entre 27.98 y 32.57 . El análisis de la derivada de la curva de disociación mostró un producto mayor expresado por los 16 animales, cuyos valores de temperatura de disociación (Tm) se encontraban entre 87.83 y $88.28^{\circ} \mathrm{C}$. A su vez, la curva mostró un producto menor presentado por 10 animales $(62.5 \%)$, cuyos valores de Tm se encontraban entre 81.57 y $82.32^{\circ} \mathrm{C}$ (Cuadro 1 ).

\section{Cuantificación relativa del gen}

Empleando el método $2^{-\Delta \Delta \mathrm{Ct}} \mathrm{y}$ tomando como punto de comparación los niveles de expresión de los calibradores, se demostró que los niveles de expresión se incrementaron con la edad, elevándose también la variabilidad de expresión del gen entre los animales mayores de tres semanas de edad (Cuadro 2). Se encontró diferencia significativa en la expresión del gen entre grupos etarios $(\mathrm{p}<0.05)$.

\section{Gen Delta ( $\delta)$}

\section{Expresión del gen}

Los valores de $\mathrm{Ct}$ de las muestras se encontraron entre 18.04 y 21.98. El análisis de la derivada de la curva de disociación mostró un producto único expresado por cada animal, cuyos valores de temperatura de disociación $(\mathrm{Tm})$ se encontraban entre $77.55 \mathrm{y}$ $77.99^{\circ} \mathrm{C}$ (Cuadro 3).

\section{Cuantificación relativa del gen}

Empleando el método $2^{-\Delta \Delta \mathrm{Ct}}$ y tomando como punto de comparación los niveles de expresión de los calibradores, se demostró que los niveles de expresión del gen se incrementaron con la edad, elevándose también la variabilidad de expresión del gen entre los animales mayores de tres semanas de edad (Cuadro 4). Existe diferencia significativa en la expresión del gen delta entre el grupo etario 4 con los demás grupos etarios.

\section{Discusión}

Se cuantificaron los valores relativos de expresión de ARNm de las cadenas gamma $(\gamma)$ y delta $(\delta)$ en la mucosa yeyunal de crías 
Cuadro 1. Valores del ciclo umbral $(\mathrm{Ct})$ y de temperatura de disociación $(\mathrm{Tm})$ del gen gamma

\begin{tabular}{cccccc}
\hline $\begin{array}{c}\text { Grupo } \\
\text { etario }\end{array}$ & Muestra & $\begin{array}{c}\text { Edad } \\
\text { (días) }\end{array}$ & $\begin{array}{c}\mathrm{Ct} \\
\text { (gamma) }\end{array}$ & $\begin{array}{c}\text { Tm } \\
\text { (producto mayor) }\end{array}$ & $\begin{array}{c}\text { Tm } \\
\text { (producto } \\
\text { menor) }\end{array}$ \\
\cline { 2 - 6 } & Calibrador 1 & Neonato & 33.30 & 88.2785 & 82.0163 \\
& Calibrador 2 & Neonato & 32.52 & 88.2785 & 82.3145 \\
\hline \multirow{4}{*}{1} & 1 & 2 & 31.76 & 88.1294556 & 81.868103 \\
& 2 & 3 & 31.59 & 88.2785339 & 82.1662598 \\
& 3 & 5 & 32.57 & 88.1294556 & 81.7190247 \\
& 4 & 2 & 31.76 & 88.1294556 & 82.1662598 \\
2 & 5 & 8 & 31.89 & 87.9803772 & 82.1662598 \\
& 6 & 8 & 31.24 & 88.1294556 & 82.3153381 \\
& 7 & 10 & 31.63 & 88.1294556 & 81.868103 \\
3 & 8 & 13 & 30.76 & 88.1294556 & - \\
& 9 & 19 & 31.85 & 87.8312912 & 81.5699463 \\
& 10 & 20 & 30.36 & 88.1294556 & 81.868103 \\
& 11 & 21 & 29.32 & 87.9803772 & - \\
& 12 & 20 & 30.36 & 87.9803772 & 81.868103 \\
4 & 13 & 38 & 28.97 & 88.1294556 & - \\
& 14 & 47 & 29.22 & 87.9803772 & - \\
& 15 & 41 & 29.82 & 87.9803772 & - \\
\hline
\end{tabular}

Cuadro 2. Cuantificación relativa del gen gamma del TCR de crías de alpacas

\begin{tabular}{|c|c|c|c|c|}
\hline \multirow[t]{2}{*}{$\begin{array}{l}\text { Grupo } \\
\text { etario }\end{array}$} & Muestra & $\begin{array}{l}\text { Edad } \\
\text { (días) }\end{array}$ & $2-\Delta \Delta \mathrm{Ct}$ & $\begin{array}{c}2-\Delta \Delta \mathrm{Ct} \\
\text { (Prom } \pm \text { D.E.) }\end{array}$ \\
\hline & $\begin{array}{l}\text { Calibrador } 1 \\
\text { Calibrador } 2 \\
\end{array}$ & $\begin{array}{l}\text { Neonato } \\
\text { Neonato }\end{array}$ & $\begin{array}{l}0.67 \\
1.49 \\
\end{array}$ & $1.08 \pm 0.6$ \\
\hline 1 & $\begin{array}{l}1 \\
2 \\
3 \\
4\end{array}$ & $\begin{array}{l}2 \\
3 \\
5 \\
2\end{array}$ & $\begin{array}{l}5.83 \\
4.86 \\
2.46 \\
5.83\end{array}$ & $4.75 \pm 1.6^{\mathrm{a}}$ \\
\hline 2 & $\begin{array}{l}5 \\
6 \\
7 \\
8\end{array}$ & $\begin{array}{c}8 \\
8 \\
10 \\
13\end{array}$ & $\begin{array}{l}4.34 \\
6.44 \\
6.78 \\
9.57\end{array}$ & $6.78 \pm 2.2^{\mathrm{ab}}$ \\
\hline 3 & $\begin{array}{c}9 \\
10 \\
11 \\
12\end{array}$ & $\begin{array}{l}19 \\
20 \\
21 \\
20\end{array}$ & $\begin{array}{c}9.30 \\
21.70 \\
12.24 \\
21.70\end{array}$ & $16.24 \pm 6.4^{b}$ \\
\hline 4 & $\begin{array}{l}13 \\
14 \\
15 \\
16\end{array}$ & $\begin{array}{l}38 \\
47 \\
41 \\
47\end{array}$ & $\begin{array}{c}103.29 \\
30.48 \\
45.04 \\
233.65\end{array}$ & $103.11 \pm 92.5^{c}$ \\
\hline
\end{tabular}


Cuadro 3. Valores del ciclo umbral $(\mathrm{Ct})$ y de temperatura de disociación $(\mathrm{Tm})$ del gen delta

\begin{tabular}{ccccc}
\hline $\begin{array}{c}\text { Grupo } \\
\text { etario }\end{array}$ & Muestra & $\begin{array}{c}\text { Edad } \\
\text { (días) }\end{array}$ & $\begin{array}{c}\mathrm{Ct} \\
\text { (delta) }\end{array}$ & Tm \\
\cline { 2 - 5 } & Calibrador 1 & Neonato & 23.47 & 77.8429489 \\
Calibrador 2 & Neonato & 23.06 & 77.5536346 \\
\hline \multirow{3}{*}{1} & 1 & 2 & 21.79 & 77.9920273 \\
& 2 & 3 & 20.54 & 77.8429489 \\
& 3 & 5 & 20.86 & 77.9920273 \\
& 4 & 2 & 21.79 & 77.9920273 \\
2 & 5 & 8 & 20.26 & 77.8429489 \\
& 6 & 8 & 19.81 & 77.8429489 \\
& 7 & 10 & 19.66 & 77.9920273 \\
& 8 & 13 & 21.04 & 77.9920273 \\
3 & 9 & 19 & 21.98 & 77.5536346 \\
& 10 & 20 & 20.34 & 77.8508453 \\
& 11 & 21 & 18.24 & 77.8429489 \\
& 12 & 20 & 20.34 & 77.70224 \\
4 & 13 & 38 & 18.04 & 77.9920273 \\
& 14 & 47 & 18.89 & 77.6938705 \\
& 15 & 41 & 20.11 & 77.8429489 \\
& 16 & 47 & 18.29 & 77.9920273 \\
\hline
\end{tabular}

Cuadro 4. Cuantificación relativa del gen gamma del TCR de crías de alpacas

\begin{tabular}{|c|c|c|c|c|}
\hline \multirow[t]{2}{*}{$\begin{array}{l}\text { Grupo } \\
\text { etario }\end{array}$} & Muestra & $\begin{array}{l}\text { Edad } \\
\text { (días) }\end{array}$ & $2^{-}-\Delta \Delta \mathrm{Ct}$ & $\begin{array}{c}2^{-\Delta \Delta \mathrm{Ct}} \\
\text { (Prom } \pm \text { D.E.) }\end{array}$ \\
\hline & $\begin{array}{l}\text { Calibrador } 1 \\
\text { Calibrador } 2 \\
\end{array}$ & $\begin{array}{l}\text { Neonato } \\
\text { Neonato }\end{array}$ & $\begin{array}{l}0.76 \\
1.31 \\
\end{array}$ & $1.04 \pm 0.4^{*}$ \\
\hline 1 & $\begin{array}{l}1 \\
2 \\
3 \\
4\end{array}$ & $\begin{array}{l}2 \\
3 \\
5 \\
2\end{array}$ & $\begin{array}{c}7.32 \\
12.8 \\
10.27 \\
7.32\end{array}$ & $9.43 \pm 2.6^{\mathrm{a}}$ \\
\hline 2 & $\begin{array}{l}5 \\
6 \\
7 \\
8\end{array}$ & $\begin{array}{c}8 \\
8 \\
10 \\
13\end{array}$ & $\begin{array}{c}17.18 \\
22.1 \\
33.8 \\
10.03\end{array}$ & $20.78 \pm 10.0^{\mathrm{a}}$ \\
\hline 3 & $\begin{array}{c}9 \\
10 \\
11 \\
12\end{array}$ & $\begin{array}{l}19 \\
20 \\
21 \\
20\end{array}$ & $\begin{array}{l}10.82 \\
28.23 \\
33.05 \\
28.23\end{array}$ & $25.08 \pm 9.8^{\mathrm{a}}$ \\
\hline 4 & $\begin{array}{l}13 \\
14 \\
15 \\
16\end{array}$ & $\begin{array}{l}38 \\
47 \\
41 \\
47\end{array}$ & $\begin{array}{c}251.32 \\
46.23 \\
47.06 \\
241.21\end{array}$ & $146.46 \pm 115.3^{b}$ \\
\hline
\end{tabular}


de alpacas aparentemente sanas, utilizando el gen de GAPDH como normalizador o control interno en el método $2^{-\Delta \Delta \mathrm{Ct}}$ (Livak y Schmittgen, 2001), uno de los genes más usados por su poca variabilidad y su expresión constante en distintos tipos celulares, y que ha sido utilizado en el análisis de la expresión relativa de péptidos antimicrobianos de la mucosa intestinal de alpacas (More et al., 2011; Siuce et al., 2015).

Los resultados muestran que, tanto los genes del polipéptido gamma como los del delta, incrementan su expresión con la edad de las crías de alpaca; sin embargo, el gen delta presenta una mayor expresión que el gamma. La formación del TCR $\gamma \delta$ se realiza con la unión de estos polipéptidos en el retículo endoplásmico de los linfocitos $\mathrm{T}$ junto a las proteínas que conforman el CD3 por acción de la glucosiltransferasa, realizando las glicosilaciones de las proteínas y formando enlaces disulfuros entre los polipéptidos, similar a lo que ocurre en la formación de los TCR $\gamma \delta$ (Gardner y Kearse, 1999). Las proporciones de expresión no son equivalentes, a pesar de que el TCR está formado solo por una cadena gamma y una cadena delta, lo cual podría deberse a los mecanismos de unión de estas cadenas con otras proteínas necesarias para su expresión, como son las proteínas $\mathrm{CD} 3$, en donde existe proteínas que se expresan y forman parten del complejo TCR-CD3 y otras que solo participan en los mecanismos de enlaces proteicos, pero no son parte del complejo, como la proteína CD3 Omega (Neisig et al., 1993).

$\mathrm{Al}$ observar los valores del método $2^{-\Delta \Delta \mathrm{Ct}}$ de ambos genes, parecería que el gen gamma se expresa menos que el gen delta, pero eso puede ser porque en el caso del gen gamma solo se está cuantificando el producto de mayor peso molecular. Los cebadores utilizados fueron de camello. Si se hubiera usado cebadores específicos de camélido sudamericano, quizás se hubiera conseguido valores del gen gamma más cercanos a los del gen delta.
En el gen gamma se evidenciaron dos productos del PCR teniendo como molde inicial a los ARN mensajeros del gen de la cadena gamma del TCR. Cada animal que presentó dos productos mostró doble temperatura de disociación (Tm). Fue así que todos los animales presentaron un producto con un mayor $\operatorname{Tm}\left(88.12^{\circ} \mathrm{C}\right)$, mientras que el $62.5 \%$ mostraron un producto de menor $\operatorname{Tm}\left(82^{\circ} \mathrm{C}\right)$, indicando que el gen al ser traducido expresa distintos ARN mensajeros. Esto es debido a que estas poliproteínas tienen una región variable que detecta a los distintos antígenos (Couedel et al., 2004) y que en este caso afectan a las alpacas. La selección negativa que ocurre en el timo (Strominger, 1989) debe también seleccionar algunos linfocitos que tienen variaciones a nivel de la expresión de regiones menos variables que pueden originar estos dos tipos de productos en el PCR. Las temperaturas de disociación entre un producto y el otro tuvieron alta diferencia, evidenciando que existe gran variabilidad entre ellos. Al analizar mediante el programa Blast al gen gamma y sus respectivos cebadores, se evidenció que el cebador «forward» se complementa con una secuencia que inducía la transcripción de un mismo gen a partir de dos puntos (nucleótidos) distintos (dato no mostrado), lo que indicaría el motivo por lo cual se obtuvo dos productos provenientes de una misma secuencia génica.

Los productos de la cadena delta mostraron temperaturas de disociación (Tm) similares entre una muestra y otra, demostrando así que se amplificó el mismo producto. Se demostró la efectividad del uso del gen de GAPDH como gen calibrador ya que se detectó en todas las crías en un nivel constante, como se ha determinado en otras especies (Kozera y Rapacz, 2013).

Observando los valores obtenidos con el método $2^{-\Delta \Delta C t}$ sobre el gen gamma, se vio que la expresión de este gen fue aumentando con la edad, siendo estadísticamente diferente a partir de la cuarta semana. Esta tendencia al incremento de la expresión de este gen 
es debido a la expansión clonal que debe estar ocurriendo en el tejido linfoide asociado en la mucosa intestinal al estar siendo colonizada por la flora microbiana intestinal, ya que estos linfocitos $T \gamma \delta$ son altamente activos en este lugar para reconocer a los antígenos y actuar como una célula presentadora de antígeno profesional (Brandes et al., 2005). La unión de los diversos antígenos producidos en el intestino en continua colonización de la flora microbiana induce a los linfocitos $\mathrm{TCR} \gamma \delta$ intraepiteliales a activar una respuesta, tanto celular como humoral, como se ha observado en el incremento de producción de IgA en la mucosa intestinal de las crías de alpacas clínicamente sanas (Dionisio et al., 2014).

\section{Conclusión}

La expresión relativa de los genes gamma y delta del receptor de linfocitos $\mathrm{T}$ en yeyuno de crías de alpaca aumenta después de la tercera semana de edad.

\section{Agradecimientos}

Se agradece a INNOVATE PERÚ por el financiamiento del presente trabajo bajo el contrato N. ${ }^{\circ} 180$ FINCYT 2013. Igualmente, se agradece al Vicerrectorado de Investigación de la Universidad Nacional Mayor de San Marcos por el apoyo económico en el desarrollo del trabajo.

\section{Literatura Citada}

\section{Brandes M, Willimann $K$, Moser B.} 2005. Professional antigen-presentation function by human $\gamma \delta \mathrm{T}$ Cells. Science 309: 264-268. doi: 10.1126/ science. 1110267

2. Couedel C, Lippert E, Bernardeau K, Bonneville M, Davodeau F. 2004. Allelic exclusion at the TCR $\delta$ locus and commitment to $\gamma \delta$ lineage: different modalities apply to distinct human $\gamma \delta$ subsets. J Immunol 172: 5544-5552. doi: 10.4049/jimmunol.172.9.5544

3. Croitoru K, Stead R, Bienenstock J, Fulop G, Harnish D, Shultz L, Jeffery P, Ernst P. 1990. Presence of intestinal intraepithelial lymphocytes in mice with severe combined immunodeficiency disease. Eur J Immunol 20: 645-651. doi: 10.1002/eji.1830200327

4. Dionisio J, Manchego A, Chiok K, Sandoval N, More J, Pezo D, Rivera H. 2014. Cinética de expresión de inmunoglobulina A en el epitelio intestinal de crías de alpaca (Vicugna pacos). Rev Inv Vet Perú 25: 151-161. doi: 10.15381/rivep.v25i2.8486

5. [FAO] Organización de las Naciones Unidas para la Agricultura y la Alimentación. 2005. Situación actual de los camélidos sudamericanos en Perú. Proyecto de cooperación técnica en apoyo a la crianza y aprovechamiento de los camélidos sudamericanos en la región andina TCP/RLA/2914. Lima: FAO. 62 p.

6. Gardner T, Kearse K. 1999. Modification of the T cell antigen receptor (TCR) complex by UDP-glucose: glycoprotein glucosyltransferase. TCR folding is finalized convergent with formation of alpha beta delta epsilon gamma epsilon complexes. J Biol Chem 274: 14094-14099. doi: 10.1074/ jbc.274.20.14094

7. Guzman E, Hope J, Taylor G, Smith A, Cubillos-Zapata C, Charleston B. 2014. Bovine $\gamma \delta \mathrm{T}$ cells are a major regulatory T cell subset. J Immunol 193: 208-222. doi: 10.4049/jimmunol.1303398

8. Gyorffy E, Glogauer M, Kennedy L, Reynolds J. 1992. T-cell receptor $\gamma \delta$ association with lymphocyte populations in sheep intestinal mucosa. Immunology 77:25-30.

9. Haas W, Pereira P, Tonegawa S. 1993. Gamma/delta cells. Annu Rev lmmunol 11: 637-685. doi: 10.1146/ annurev.iy.11.040193.003225

10. Kozera B, Rapacz M. 2013. Reference genes in real-time PCR. J Appl Genet 54: 391-406. doi: 10.1007/s13353-013-0173-x 
11. Livak K, Schmittgen T. 2001. Analysis of relative gene expression data using real time quantitative PCR and the $2^{-\Delta \Delta C t}$. Methods 25: 402-408. doi: 10.1006/ meth.2001.1262

12. Mamani J, Condemayta Z, Calle L. 2009. Causas de mortalidad de alpacas en tres principales centros de producción ubicados en puna seca y húmeda del departamento de Puno. REDVET 10(8). [Internet]. Disponible en: http:// www.redalyc.org/articulo.oa?id $=63617143002$

13. More J, Manchego A, Sandoval N, Ramírez M, Pezo D, Chiok K, Rivera H. 2011. Detección genómica y expresión de péptidos antimicrobianos $(\alpha-\mathrm{y}$ ß-defensinas) en mucosa intestinal de crías de alpaca (Vicugna pacos). Rev Inv Vet Perú 22: 324-335. doi: 10.15381/ rivep.v22i4.332

14. More J. 2013. Efecto de antígenos clostridiales con ácido retinoico sobre la expresión de citoquinas de la respuesta inmune humoral y celular de la mucosa intestinal de crías de alpacas (Vicugna pacos). Tesis de Magíster. Lima: Univ Nacional Mayor de San Marcos. 104 p.

15. Neisig A, Vangsted A, Zeuthen J, Geisler $C$. 1993. Assembly of the T-cell antigen receptor. Participation of the CD3 omega chain. J Immunol 151: 870-879.
16. Pfaffl M. 2001. A new mathematical model for relative quantification in real-time RT-PCR. Nucleic Acids Res 29: e45.

17. Rebrikov D, Trofimov D. 2006. Realtime PCR: a review of approaches to data analysis. Prikl Biokhim Mikrobiol 42: 455-463 [en ruso]. doi: 101134/ S0003683806050024

18. Rojas M, Manchego A, Rocha CB, Fornells LA, Silva RC, Mendes GS, Dias HG, et al. 2016. Outbreak of diarrhea among preweaning alpacas (Vicugna pacos) in the southern Peruvian highland. J Infect Dev Ctries 10:269-274. doi: 10.3855/jidc.7398

19. Siuce J, Manchego A, Sandoval $N$, More J, Chiok K, Pezo D, Rivera H. 2015. Expresión de defensinas en yeyuno de crías de alpacas (Vicugna pacos) con enteropatías. Rev Inv Vet Perú 26: 317-327. doi: 10.15381/ rivep.v26i2.11093

20. Steel R, Torrie J. 1988. Bioestadística: principios y procedimientos. $2^{\mathrm{a}} \mathrm{ed}$. México: McGraw-Hill Interamericana. México. $622 \mathrm{p}$.

21. Strominger J. 1989. Developmental biology of T cell receptors. Science 244: 943-950. doi: 10.1126/science. 2658058

22. Tizard I. 2002. Inmunología veterinaria. $6^{\mathrm{a}}$ ed. México: McGraw-Hill Interamericana. $517 \mathrm{p}$. 